\title{
Pharmacological Adherence to Oral Anticoagulant and Factors that Influence the International Normalized Ratio Stability
}

\author{
Christiane Wahast Ávila ${ }^{1}$ \\ Graziella Badin Aliti \\ Maria Karolina Ferreira Feijó ${ }^{1}$ \\ Eneida Rejane Rabelo ${ }^{3}$
}

\begin{abstract}
Cross-sectional study developed to relate the international normalized ratio (INR), used as a parameter to monitor the levels of blood clotting, stability to adherence, age, level of education, socioeconomic level, interaction with other drugs, comorbidities, vitamin $\mathrm{K}$ intake, anticoagulation time and drug cost. 156 patients were included, mean age $57 \pm 13$ years, $(53.8 \%)$ male, $61(39.1 \%)$ had high adherence, $91(58.3 \%)$ medium and $4(2.6 \%)$ low adherence to treatment, $117(75 \%)$ had INR stability up to $50 \%$ and $39(25 \%) \geq 75 \%$, patients with shorter time of anticoagulation presented higher stability, those who spent less on the drug remained more stable and had better adherence. It was concluded that more than $90 \%$ of patients had high and medium adherence and that the anticoagulation time and drug cost were the factors related to the anticoagulation stability.
\end{abstract}

Descriptors: Anticoagulants; International Normalized Ratio; Monitoring, Ambulatory.

\footnotetext{
${ }^{1}$ RN, Hospital de Clínicas de Porto Alegre, RS, Brazil. Master's Students, Programa de Pós-Graduação em Enfermagem, Escola de Enfermagem, Universidade Federal do Rio Grande do Sul, RS, Brazil. E-mail: Christiane - chriswavila@yahoo.com.br, Maria Karolina - mariakarolinafeijo@gmail.com.

${ }^{2}$ RN, M.Sc. in Cardiovascular Science, Hospital de Clínicas de Porto Alegre, RS, Brazil. E-mail: grazialiti@gmail.com.

${ }^{3}$ RN, Ph.D. in Biological Sciences, Adjunct Professor, Escola de Enfermagem, Universidade Federal do Rio Grande do Sul, RS, Brazil. E-mail: eneidarabelo@gmail.com.
}

Corresponding Author: Eneida Rejane Rabelo Universidade Federal do Rio Grande do Sul. Escola de Enfermagem. Departamento de Enfermagem Médico-Cirurgica. Rua São Manoel, 963 Bairro Rio Branco 


\title{
Adesão farmacológica ao anticoagulante oral e os fatores que influenciam na estabilidade do índice de normatização internacional
}

Este é um estudo transversal, desenvolvido com o objetivo de relacionar a estabilidade do índice de normatização internacional (INR), utilizado como parâmetro para monitorar os níveis de coagulação do sangue, com adesão, idade, escolaridade, nível socioeconômico, interação com outras medicações, comorbidades, ingesta de vitamina $K$, tempo de anticoagulação (ACO) e custo com medicações. Incluíram-se 156 pacientes, idade média $57 \pm 13$ anos, 53,8\% pertencente ao sexo masculino; 61 (39,1\%) tiveram alta adesão, $91(58,3 \%)$ média e $4(2,6 \%)$ baixa adesão ao tratamento; $117(75 \%)$ apresentaram estabilidade do INR de até $50 \%$ e $39(25 \%) \geq$ a $75 \%$; pacientes com menor tempo de ACO apresentaram maior estabilidade; aqueles que gastavam menos com a medicação permaneciam mais estáveis e com melhor adesão. Concluiu-se que mais de $90 \%$ dos pacientes apresentaram alta e média adesão referida, e que tempo de anticoagulação e custo com a medicação foram os fatores relacionados à estabilidade da ACO.

Descritores: Anticoagulantes; Coeficiente Internacional Normatizado; Monitorização Ambulatorial.

\section{Adhesión farmacológica al anticoagulante oral y factores que influyen en la estabilidad del índice de estandarización internacional}

\begin{abstract}
Se trata de un estudio transversal, desarrollado con el objetivo de relacionar la estabilidad del índice de estandarización internacional (INR), utilizado como parámetro para monitorizar los niveles de coagulación de la sangre, con adhesión, edad, escolaridad, nivel socioeconómico, interacción con otras medicaciones, comorbilidad, ingesta de vitamina $\mathrm{K}$, tiempo de anticoagulación (ACO) y costo con medicamentos. Se incluyeron 156 pacientes, edad promedio $57 \pm 13$ años, 53,8\% perteneciente al sexo masculino; $61(39,1 \%)$ tuvieron alta adhesión, $91(58,3 \%)$ promedio y $4(2,6 \%)$ baja adhesión al tratamiento; 117 (75\%) presentaron estabilidad del INR de hasta $50 \%$ y $39(25 \%) \geq$ a $75 \%$; los pacientes con menor tiempo de ACO presentaron mayor estabilidad; aquellos que gastaban menos con la medicación permanecían más estables y con mejor adhesión. Se concluyó que más del $90 \%$ de los pacientes presentaron adhesión alta y promedio, y que el tiempo de anticoagulación y el costo con la medicación fueron los factores relacionados a la estabilidad de la $\mathrm{ACO}$.
\end{abstract}

Descriptores: Anticoagulantes; Relación Normalizada Internacional; Monitoreo Ambulatorio.

\section{Introduction}

The use of anticoagulant therapy has significantly increased in the last decades due to its proven effectiveness and safety, besides its numerous indications $^{(1)}$. The indications of this therapy include prevention and treatment of deep venous thrombosis, extensive anterior acute myocardial infarction, prosthetic and bioprosthetic heart valves (in the first 3 months), atrial fibrillation, intracardiac thrombi and others ${ }^{(2)}$.
However, anticoagulant therapy instability has been a problem since the discovery of cumarinic drugs ${ }^{(3)}$.

Anticoagulation (ACO) stability is related to adherence, as well as several other factors, such as age, concomitant use of other drugs, comorbidities, genetic polymorphisms and vitamin $\mathrm{K}$ intake ${ }^{(4)}$. The importance of the diet is often cited in educational programs for patients in outpatient anticoagulation therapy and 
various nutrients, especially vitamin $K$, have been remembered in the nutrient-drug interactions with coumarin derivatives ${ }^{(3)}$. Vitamin $\mathrm{K}$ is an essential cofactor for the synthesis of carboxyglutamic acid, a critical step in the activation of 4 coagulation factors (II, VII, IX, and $X$ ) and proteins $C$ and $S^{(5)}$. Although the impact of dietary vitamin $\mathrm{K}$ intake on long term oral anticoagulation has been recognized for 30 years $^{(6)}$, recent prospective evidence suggests that this interaction is clinically relevant and might be a major independent factor that interferes with anticoagulation stability ${ }^{(7)}$.

Drug cost should also be considered as one of the causes that interfere in treatment adherence. This factor is undoubtedly a great obstacle to adherence and, therefore, it should be contextualized mainly in developing countries, where access to drugs is often limited(8).

Several studies have been conducted for the purpose of evaluating the patients' knowledge of oral anticoagulant treatment, its effects and complications ${ }^{(9-10)}$. In this context, a review article identified eight instruments in the literature. However, these authors emphasize that there is little evidence for the selection of a specific instrument to actually evaluate the patients' knowledge and therapeutic implications, and that each country should validate its own instrument adapted to its culture and, in this way, evaluate also this factor as an intervention in ACO adherence and stability ${ }^{(11)}$.

Recent studies comparing patients monitored by specialists at anticoagulation clinics and monitored under systematic education on the anticoagulant therapy show a better control of the international normalized ratio (INR) within the therapeutic range $\mathrm{e}^{(12-13)}$. In this context, a cross-sectional study that included 52 patients compared the effects of education on adherence, knowledge and quality of life at two ACO clinics, and found that ACO control is associated with adequate adherence and does not involve demographic variables, knowledge on the utilized therapy or perception of quality of life ${ }^{(14)}$.

The investigation of factors like adherence, age, level of education, socioeconomic level, interaction with other drugs, comorbidities, vitamin $\mathrm{K}$ intake, anticoagulation time, drug cost and INR stability remains poorly explored in literature.

Considering the large number of patients with precise indications of oral anticoagulation and the evidence that, even if accompanied by an outpatient clinic, they do not reach therapeutic levels of INR, it is essential to identify factors that may be related to compliance and, hence, to instability of anticoagulation.

\section{Objective}

To evaluate the factors that can interfere in treatment adherence and INR stability.

\section{Methods}

A cross-sectional correlational study was developed at an ACO outpatient clinic of a federal public teaching hospital in southern Brazil, from August 2007 to January 2008. The study included consecutively, through a convenience sample, chronically anticoagulated patients with any clinical indication; of both genders and $\geq 18$ years of age; taking Warfarin $5 \mathrm{mg}$ or Marcoumar $3 \mathrm{mg}$. The study excluded patients with cognitive deficit or neurological sequelae that could affect the way the instrument is completed. The study was approved by the institution's ethics committee, protocol number 07334 . The patients who agreed to participate in the study signed the Informed Consent Form.

The Morisky Adherence Scale was applied for the evaluation, comprising four Likert-type questions with a score ranging from zero (high adherence) to four (low adherence). The patient was classified in the high adherence level group when the answers to all questions were negative and in the medium adherence level group with one or two affirmative answers. However, with three or four affirmative answers, the patient was classified in the low adherence level group ${ }^{(15)}$.

This scale has been used in Brazil in different scenarios. Recently, it has been used in hypertensive patients to assess adherence to drug and nonpharmacological treatment ${ }^{(16)}$ and also in patients on chronic oral anticoagulation(17). Moreover, this same scale was also used to assess the validity of four indirect methods of measuring medication adherence in hypertensive patients ${ }^{(18)}$.

The INR stability was calculated using the INR number within the therapeutic range divided by the collected INR number (for example, a patient with an INR target of 2.0-3.0 - INR1 $=2.0$, INR2 $=1.5$, INR3 = 2.4 , INR4 $=1.85$, INR5 $=3.0: 3$ values within the target level, presented $60 \%$ stability). INR has been proposed as a way to eliminate inter-laboratory differences in test results caused by the use of thromboplastins with different sensitivities. The INR is calculated by raising the prothrombin time ratio (PTR; the patient's prothrombin time divided by a reference normal prothrombin time) to the power of a coefficient known as the international sensitivity index (ISI). This coefficient relates the 
sensitivity for monitoring warfarin therapy of a given thromboplastin to the sensitivity of the World Health Organization's first primary international reference preparation of thromboplastin, which was assigned an ISI of $1.0^{(19)}$. An instrument was elaborated for this study with clinical and demographic variables. As it was not possible to measure the exact amount of vitamin $\mathrm{K}$ intake, this information was estimated considering the number of times the patients consumed vitamin K-rich foods in the week prior to the INR test, according to what they reported on the clinical evaluation form.

Major bleeding event was defined as a fatal and symptomatic one; and/or decrease in hemoglobin of at least $3.0 \mathrm{~g} / \mathrm{dL}$, and/or bleeding requiring transfusion of two or more units of red blood cells. Any other bleeding considered significant and not meeting the criteria of major bleeding was considered minor bleeding(20).

\section{Data Analysis}

The analyses were performed using Statistical Package for Social Sciences 14.0. Continuous variables were expressed as mean \pm standard deviation to data of normal distribution and as median and interquartile interval to non-parametric data. Categorical variables are expressed as percentages. The Mann-Whitney test was utilized in non-parametric data associations. A twotailed $\mathrm{P}$ value below 0.05 was considered statistically significant. Considering $80 \%$ power and 5\% significance level to detect a $23 \%$ stability difference among patients with good and bad reported adherence, it was necessary to include 156 patients.

\section{Results}

This study included 156 chronically anticoagulated patients. Mean age was $57.4 \pm 13$ years (ranging between 25 and 82 years), 84 (53.8\%) of the patients were male and presented a median $2(1-4)$ years of level of education, and most were inactive 121 (77.6\%). The average monthly income was $633 \pm 454 \mathrm{U} \$$ and the median monthly cost of anticoagulation was 8.3 (5.6-11). The main indication for oral anticoagulation use in the studied population was atrial fibrillation in 53 (34.2\%) patients. The median duration of anticoagulation was 27.5 (10-52) months, ranging from shorter than 1 month to a maximum of 216 months. A median duration of anticoagulation group was 12 (3-31) months. The most common anticoagulant was Warfarin 135 (86.5\%), with a maximum dose of $93 \mathrm{mg}$ per month. In those patients using acetylsalicylic acid, 65 (41.9\%) ingested
$100 \mathrm{mg}$ and 5 (3.2\%) ingested 200mg. Table 1 shows these characteristics.

Table 1 - Demographic and clinical characteristics of anticoagulated patients. Porto Alegre 2008

\begin{tabular}{|c|c|}
\hline Age (years)* & $57.4 \pm 13$ \\
\hline Gender (male) $)^{\dagger}$ & $84(53.8)$ \\
\hline Level of education (years) $)^{\ddagger}$ & $2(1-4)$ \\
\hline Marital status (married) ${ }^{\dagger}$ & $120(76.9)$ \\
\hline Lives with relative $^{\dagger}$ & $144(92,9)$ \\
\hline \multicolumn{2}{|l|}{ Occupation $^{\dagger}$} \\
\hline Full time & $35(22.4)$ \\
\hline Retired & $121(77.6)$ \\
\hline Monthly income U\$* & $633 \pm 454$ \\
\hline Monthly cost of anticoagulant U $\$^{\ddagger}$ & $8.3(5.6-11)$ \\
\hline \multicolumn{2}{|l|}{ Anticoagulation indication ${ }^{\dagger}$} \\
\hline Atrial fibrillation & $53(34)$ \\
\hline Mitral mechanical prosthesis & $45(28.8)$ \\
\hline Aortic mechanical prosthesis & $43(27.6)$ \\
\hline Others & $15(9.6)$ \\
\hline Anticoagulation time (months) $)^{\ddagger}$ & $27.5(10-52)$ \\
\hline Group time (months) $)^{\ddagger}$ & $12(3-31)$ \\
\hline \multicolumn{2}{|l|}{ Anticoagulant drug ${ }^{\dagger}$} \\
\hline Warfarin $5 \mathrm{mg}$ & $135(86.5)$ \\
\hline Marcoumar 3mg & $21(13.5)$ \\
\hline \multicolumn{2}{|l|}{ Drugs that interfere ${ }^{\dagger}$} \\
\hline Acetylsalicylic acid $100 \mathrm{mg}$ & $65(41.9)$ \\
\hline Others & $102(63.8)$ \\
\hline
\end{tabular}

*Values expressed as mean \pm standard deviation, ${ }^{+} n$ (\%) categorical variables, " ${ }^{\ddagger}$ median ( 25 and 75 percentiles)

Table 2 shows adherence to the pharmacological treatment classified as high, medium and low adherence. It is noted that more than $90 \%$ of patients are classified between medium and high adherence.

Table 2 - Anticoagulated patients and Morisky Adherence Scale. Porto Alegre, 2008

\begin{tabular}{llcc}
\hline \multicolumn{1}{c}{ Adherence } & Patients answered "yes" in: & $\begin{array}{c}\mathbf{N} \\
\mathbf{( 1 5 6 )}\end{array}$ & $\%$ \\
\hline High & 0 (no question) & 61 & 39.1 \\
Medium & 1 question & 42 & 26.9 \\
& 2 questions & 49 & 31.4 \\
\multirow{2}{*}{ Low } & 3 questions & 4 & 2.6 \\
& 4 questions & 0 & 0 \\
\hline
\end{tabular}

* Categorical variables $\mathrm{n}(\%)$.

Regarding INR stability, 117 (75\%) patients showed with stability up to $50 \%$ and $39(25 \%)$ presented stability of $75 \%$ or above. When stability was related to factors like adherence, age, level of education, socioeconomic level, interaction with other drugs, comorbidities 
and vitamin $\mathrm{K}$ intake, no significant association was observed. Patients with shorter anticoagulation time presented greater stability than longtime anticoagulated patients. The monthly cost was another factor related to INR stability, with patients who spent less with the drug remaining more stable $(P<0.05)$. Table 3 shows these data.

Table 3 - Factors related to the INR stability of anticoagulated patients. Porto Alegre, 2008

\begin{tabular}{lcccc}
\hline & Stability & Stability & \multirow{2}{*}{$\mathbf{P}^{\dagger}$} \\
\cline { 2 - 3 } & $\mathbf{2 7 5 \%}$ & up to $\mathbf{5 0 \%}$ & \\
\hline Anticoagulation time (months) & $18(7-36)$ & $36(12-60)$ & $<0.05$ \\
Monthly cost U\$ & $6.6(5-10.5)$ & $8.3(5.6-11)$ & $<0.05$ \\
\hline
\end{tabular}

* Values expressed as median (percentage: 25 ; percentage: 75 ). ${ }^{+}$Tests utilized: Mann-Whitney

Sixty-eight $(42.5 \%)$ of the patients evaluated failed to take the anticoagulant at least once, and 57 (83.8\%) of them presented up to $50 \%(P<0.05)$ stability.

Regarding the occurrence of previous complications (hemorrhagic or thromboembolic events), 4 (2.6\%) patients presented thromboembolic events during the treatment. Hemorrhagic events were the most prevalent, $41(26.5 \%)$ of the patients presented mild bleeding and $17(11 \%)$ heavier bleeding. When the occurrence of these events was related to adherence to the pharmacological treatment, use of drugs that interact with cumarinic drugs or occurring during the ACO time, no significant relation was found.

Regarding the factors that influenced adherence to the pharmacological treatment, a significant association was found between drug cost and adherence to pharmacological treatment. Among patients who presented satisfactory adherence, 61 (38.12\%) spent a median of U\$7.8 (5.5-9.4) on the drug and patients that presented low or medium adherence spent median of U\$10 (6.7-11) $(\mathrm{P}<0.05)$ with the anticoagulant.

\section{Discussion}

This study demonstrated that little over half the patients presented medium or low reported adherence. Even linked with a specific outpatient clinic and receiving regular monitoring, only 39 (25\%) presented a stability of $75 \%$ or higher. The factors related to stability were: anticoagulation time and drug cost. In addition, a significant association was found between drug cost and treatment adherence. There was a small number of thromboembolic events, although some cases of underanticoagulation were registered. Bleeding episodes were mostly minor.

The time the patients remained within the target INR was shorter than the time published at the seventh conference of the American College of Chest Physicians about antithrombotic and thrombolytic treatment, from 2004, which reports that studies with target INR achieved 50 to $70 \%$ of the time, approximately ${ }^{(3)}$. However, the low percentage of patients who achieved the target INR in this study agrees with the data in the international literature. Even studies conducted in developed countries, with a more educated population, demonstrate low stability rates ${ }^{(21)}$. Therefore, the fact of belonging to a developed country or having a higher level of education does not seem to matter, as the problem of indication for chronic treatment with frequent monitoring seems to be similar in all patients.

Although some studies in the literature have demonstrated that anticoagulation stability is related to factors like adherence, age, level of education, socioeconomic level, interaction with other drugs, comorbidities and vitamin $\mathrm{K}$ intake ${ }^{(4,22)}$, no association with these factors was found in this study. These data were also recently demonstrated in a study conducted in specialized outpatient clinics in Brazil(17). It can be concluded that this is due to differences in the evaluation methods that were used in studies demonstrating the impact of adherence on INR stability. Other evaluation instruments were also utilized, such as electronic devices $^{(13)}$.

The mean age of patients included in the study was 57 years, a different characteristic from what was found in other studies that demonstrate that elderly patients, over 70 years old, have less adequate control of ACO, with bleeding as the most frequent complications in this population (23). In this scenario, education and systematic nursing monitoring has shown satisfactory results in the reduction of thrombotic events or bleedings, which involves improved quality of life for these patients ${ }^{(12)}$.

Many patients used one or more drugs interacting with warfarin, but the occurrence of complications or INR instability was not attributed to the concomitant use of these drugs, as the most frequent drugs utilized by the patients (propranolol, simvastatin, omeprazole, amiodarone, etc.), except for acetylsalicylic acid, were classified as having little probability of interaction, according to a systematic review published in 2005. This review also demonstrated that, although the number of drugs that interact with warfarin keeps increasing, only small studies have been conducted so far ${ }^{(24)}$. Co- 
administration of acetylsalicylic acid (aspirin) and warfarin increases the risk of bleeding. The mechanisms of this adverse interaction are antiplatelet effects, gastric mucosal damage and a hypothrombinemic response to warfarin (with an aspirin dosage of 2 to $4 \mathrm{~g}$ per day)(25).

Some randomized clinical trials on diet strategy have demonstrated the impact of changes in vitamin $\mathrm{K}$ intake on $\mathrm{ACO}$ control(3-4,22). As our study is an observational study and does not regard diet strategy, it was impossible to actually demonstrate the influence of vitamin $\mathrm{K}$ intake on the stability of these patients.

Anticoagulation time and drug cost were related to INR stability, with short-time anticoagulated patients and patients who spent less on the drug remaining more stable. However, no study was found in literature that has related these factors to anticoagulation stability. The reason why short-time anticoagulated patients presented higher stability can be related to more intensive monitoring, which is performed at the beginning of the treatment with anticoagulation, when more dose adjustments are required. The lack of financial resources was the main reason to interrupt treatment, which contributed to greater instability of the patients. However, these are data from the time of the interview and may not reflect the true influence of the lack of resources throughout the treatment.

Few patients presented complications. Hemorrhagic complications, especially intracranial and gastrointestinal types, are most frequently expected when oral anticoagulation is prescribed ${ }^{(26)}$. According to data presented in an international consensus, the main determinants of bleeding are INR oscillation, INR values above five and concomitant use of other drugs (especially platelet anti-aggregating substance). Despite this, the annual rates of clinically relevant bleeding (intracerebral and gastrointestinal tract hemorrhage are around $1.3 \%$ when the INR remains within the therapeutic range from two to three, which corresponds to approximately the value found in this study(27).

Patients who presented satisfactory adherence spent less on the drug compared with those who presented medium or low adherence. We found results similar to another classical study that attempted to evaluate the drug cost impact on adherence to the pharmacological treatment. In this study, the main factor reported for non-adherence to treatment by elderly people was the high cost of the drug. Besides, the cost of drugs prescribed to non-adherent patients was on average twice as high as the cost of drugs prescribed to patients who adhered to the treatment ${ }^{(8)}$. This factor is undoubtedly a great obstacle to adherence and should be one of the contextualized aspects, especially in developing countries.

However, some studies that report high nonadherence rates do not refer to drug availability. For example, a study published in 2009 about factors associated to patients' noncompliance with hypertension treatment according to the Morisky-Green protocol found that $86.76 \%$ did not comply with the medication regimen and the reasons reported for non-adherence to medication included: cannot tell the reason $(P=0.006)$, associated diseases $(P=0.049)$ and alcohol consumption $(P=0.013)^{(28)}$. Beyond the question of costs, other factors may be associated with non-adherence when comparing treatments of continued use in chronic disease.

Therefore, only by knowing the forms of access to drugs will we be able to ask questions about treatment adherence. However, recent studies that compare patients under monitoring by specialized professionals at anticoagulation clinics and monitoring under systematic education have presented positive results in terms of improved adherence and patient's knowledge on the adopted therapy ${ }^{(12-13)}$.

\section{Study limitations}

The Morisky adherence scale is widely utilized to evaluate adherence to drug therapy, but we found some limitations when applying it. This test tends to overestimate non-adherence and does not provide the patient with an opportunity to express his/her difficulties and understanding related to the treatment. Therefore, the development of other instruments to evaluate adherence is required, especially in patients who use ora anticoagulants. Another factor identified as a limitation was the form of evaluating vitamin $\mathrm{K}$ intake, because we know that an inconsistent intake can contribute to changes in INR levels. Other studies with an appropriate design to assess a combination with other factors, such as alcohol consumption and presence of genetic polymorphisms, may yield more conclusive results.

\section{Conclusions}

Over $90 \%$ of the patients presented high and medium reported adherence. Anticoagulation time and drug cost were the factors with the highest correlation with ACO stability.

Based on the results of this study, it was possible to demonstrate that factors like adherence, age, level of education, socioeconomic level, interaction with 
other drugs, comorbidities and vitamin $\mathrm{K}$ intake did not influence INR stability. However, the results show that anticoagulation time and economic difficulties constitute barriers to anticoagulation treatment adherence and that some professionals often undervalue the unavailability of access to the drug. Knowing these data may permit the development of specific strategies in the scenario of an outpatient clinic service, elaborated by nurses, further qualifying nurse monitoring and, consequently, improving treatment adherence, quality, understanding, patient care, and minimizing the risk of thromboembolic and hemorrhagic complications.

Considering the high number of patients with a precise indication for oral anticoagulation and who do not achieve therapeutic levels of INR even when monitored at a specialized outpatient clinic, it is essential to identify clinical predictors of underanticoagulation and overanticoagulation. New studies are required to identify and remove obstacles to adequate and safe chronic anticoagulation.

\section{References}

1. Ansell JE, Buttarom ML, Thomas OV, Knowlton $\mathrm{CH}$. Consensus guidelines for coordinated outpatient an oral anticoagulation therapy management: Anticoagulation guidelines task force. Ann Pharmacother. 1997;31:604-15.

2. Hirsh J, Fuster V, Ansell J, Halperin JL. American Heart Association/American College of Cardiology Foundation Guide to Warfarin Therapy. Circulation. 2003; 107:1692-711.

3. Ansell J, Hirsh J, Poller L, Bussey H, Jacobson A, Hylek $E$. The pharmacology and management of the vitamin k antagonist: The seventh ACCP conference on antithrombotic and thrombolytic therapy. Chest. 2004;126 Suppl: 204S-33S.

4. Sconce E, Avery P, Wynne H, Kamali F. Vitamin K supplementation can improve stabilitity of anticoalation for patients with unexplained variability in response to Warfarin. Blood. 2007;109(6):2419-22.

5. Rohde LE, de Assi MC, Rabelo ER Dietary vitamin K intake and anticoagulation in elderly patients. Curr Opin Clin Nutr Metab Care. 2007;10:1-5.

6. Udall JA. Human sources and absorption of vitamin $\mathrm{K}$ in relation to anticoagulation stability. JAMA. 1965;194:127-9.

7. Schurgers LJ, Shearer MJ, Hamulyák K, Stöcklin E, Vermeer $\mathrm{C}$. Effect of vitamin $\mathrm{K}$ intake on the stability of oral anticoagulant treatment: dose response relationships in healthy subjects. Blood. 2004;104:2682.
8. Leite SN, Vasconcellos MPC. Adesão à terapêutica medicamentosa: elementos para a discussão de conceitos e pressupostos adotados na literatura. Cad Saúde Colet. 2003; 8(3):775-82.

9. Zeolla MM, Brodeur RR, Dominelli A, Haines ST, Allie ND. Development and validation of an instrument to determine patient knowledge: the oral anticoagulation knowledge test. Ann Pharmacother. 2006;40:633-8.

10. Briggs $A L$, Jackson TR, Bruce $S$, Shapiro NL. The development and performance validation of a tool to assess patient anticoagulation knowledge. Res Social Adm Pharm. 2005;1(1):40-59.

11. Van Damme S, Van Deyk K, Moons $P$, Verhamme P, Budts W. Instruments to assess patient's knowledge regarding oral anticoagulation therapy: a systematic review. Eur J Cardiovasc Nurs. 2008;7 Suppl 1:21-2.

12. Shimabukuro TT, Kramer J, Mcguire M. Development and implementation of a nurse-managed anticoagulation program. J Health Qual. 2004;26(1):4-13.

13. Khan TI, Kamali F, Kesteven P, Avery P, Wynne $H$. The value of education and self-monitoring in the management of warfarin therapy in older patients with unstable control of anticoagulation. $\mathrm{Br} \mathrm{J}$ Haematol. 2004;126(4):557-64.

14. Davis, NJ, Billet $\mathrm{HH}$, Cohen HW, Arnsten JH. Impact of adherence, knowledge, and quality of life on anticoagulation control. Ann. Pharmacother. 2005;39(34):632-6.

15. Morisky DE, Green LW, Levine DM. Concuurent and predictive validity of a self-reported measure of medication adherence. Med Care.1986;24(1):67-74.

16. Dosse C, Cesarino CB, Martin JFV, Castedos MCA. Fatores associados a não adesão dos pacientes ao tratamento de hipertensão arterial. Rev. Latino-Am. Enfermagem. 2009; 17(2):201-6.

17. Esmerio FG, Souza EM, Leiria TL, Lunelli R, Moraes MA. Uso crônico de anticoagulante oral: implicações para o controle de níveis adequados. Arq. Bras. Cardiol. 2009;93(5):549-54.

18. Prado JC, Kupek E, Mion D. Validity of indirect methods to measure adherence in primary care hypertensives. J Human Hypertens. 2007;21:579-84.

19. Dzung TL, Weibert RT, Sevilla BK, Donnelly KJ, Rapaport SI. The International Normalized Ratio (INR) for Monitoring Warfarin Therapy: Reliability and Relation to Other Monitoring Methods. Ann Intern Med. 1994; 120:552-8.

20. Budaj A, Eikelboom JW, Mehta SR, Afzal R, Chrolavicius S, Bassand J-P, et al. Improving clinical outcomes by reducing bleeding in patients with non- 
ST-elevation acute coronary syndromes. Eur Heart J. 2009;30(6):655-61.

21. Schmitt L, Speckman J, Ansell J. Quality assessment of anticoagulation dose management: comparative evaluation of measures of time-in-therapeutic range. J Thromb Thrombolysis. 2003;15(3):213-6.

22. Assis MC, Rabelo ER, Ávila CW, Polanczyk CA, Rohde EL. Improved oral anticoagulation after a dietary vitamin k-guided strategy: a randomized controlled trial. Circulation. 2009;120:1115-22.

23. Pautas E, Gouin-Thibault I, Debray M, Gaussem $P$, Siguret V. Haemorrhagic complications of vitamin $k$ antagonists in the elderly: risk factors and management. Drugs Aging. 2006;23:13-25.

24. Holbrook A, Pereira JA, Labiris R, Mcdonald $H$, Douketis JD, Crowther $M$, et al. Systematic overview of warfarin and its drug and food interactions. Arch Intern Med. 2005; 165:1095-106.

25. Chan TY. Adverse interactions between warfarin and nonsteroidal antiinflammatory drugs: mechanisms, clinical significance, and avoidance. Ann Pharmacother. 1995; 29:1274-83.

26. Schulman S, Beyth RJ, Kearon C, Levine MN. Hemorrhagic Complications of Anticoagulant and Thrombolytic Treatment American College of Chest Physicians Evidence- Based Clinical Practice Guidelines (8th Edition). Chest. 2008;133(6):257S-98S.

27. Levine MN, Raskob G, Beyth RJ, Kearon C, Shulman S. Hemorrhagic complications of anticoagulant treatment. Chest. 2004;126(3):287S-310S.

28. Dosse C, Cesarino CB, Martin JFV, Castedo MCA. Factors associated to patients' noncompliance with hypertension treatment. Rev. Latino-Am. Enfermagem. 2009;17(2):201-6. 